\title{
The epidemiologic impact and cost- effectiveness of new tuberculosis vaccines on multidrug-resistant tuberculosis in India and China
}

Chathika K Weerasuriya ${ }^{1 *}$, Rebecca C Harris ${ }^{1,2}$, C Finn McQuaid ${ }^{1}$, Fiammetta Bozzani ${ }^{3}$, Yunzhou Ruan ${ }^{4}$, Renzhong Liं, Tao Li ${ }^{4}$, Kirankumar Rade ${ }^{5}$, Raghuram Rao ${ }^{6}$, Ann M Ginsberg ${ }^{7,8}$, Gabriela B Gomez ${ }^{3,9+}$ and Richard G White ${ }^{1+}$

\begin{abstract}
Background: Despite recent advances through the development pipeline, how novel tuberculosis (TB) vaccines might affect rifampicin-resistant and multidrug-resistant tuberculosis (RR/MDR-TB) is unknown. We investigated the epidemiologic impact, cost-effectiveness, and budget impact of hypothetical novel prophylactic prevention of disease TB vaccines on RR/MDR-TB in China and India.

Methods: We constructed a deterministic, compartmental, age-, drug-resistance- and treatment history-stratified dynamic transmission model of tuberculosis. We introduced novel vaccines from 2027, with post- (PSI) or both preand post-infection (P\&PI) efficacy, conferring 10 years of protection, with 50\% efficacy. We measured vaccine costeffectiveness over 2027-2050 as USD/DALY averted-against 1-times GDP/capita, and two healthcare opportunity cost-based (HCOC), thresholds. We carried out scenario analyses.

Results: By 2050, the P\&PI vaccine reduced RR/MDR-TB incidence rate by 73\% (UI:66-76) and 72\% (UI:65-77), and the PSI vaccine by $29 \%$ (UI: 27-31) and 47\% (UI: 37-58) in China and India, respectively.

In India, we found both USD 10 P\&PI and PSI vaccines cost-effective at the 1-times GDP and upper HCOC thresholds and P\&PI vaccines cost-effective at the lower HCOC threshold. In China, both vaccines were cost-effective at the 1times GDP threshold. P\&PI vaccine remained cost-effective at the lower HCOC threshold with $49 \%$ probability and PSI vaccines at the upper HCOC threshold with $21 \%$ probability. The P\&PI vaccine was predicted to avert 1.0 million (UI: 0.6-1.3) and 0.8 million (UI: 0.5-1.4) second-line therapy regimens in China and India between 2027 and 2050, respectively.
\end{abstract}

Conclusions: Novel TB vaccination is likely to substantially reduce the future burden of RR/MDR-TB, while averting the need for second-line therapy. Vaccination may be cost-effective depending on vaccine characteristics and setting.

Keywords: Tuberculosis, Drug resistance, Vaccine, Mathematical model

\footnotetext{
* Correspondence: c.weerasuriya@lshtm.ac.uk

${ }^{\dagger}$ G. B. Gomez and R. G. White contributed equally to this work.

${ }^{1}$ TB Modelling Group, TB Centre and Centre for the Mathematical Modelling

of Infectious Diseases, Department of Infectious Disease Epidemiology,

Faculty of Epidemiology \& Population Health, London School of Hygiene

and Tropical Medicine, London, UK

Full list of author information is available at the end of the article
}

(c) The Author(s). 2021 Open Access This article is licensed under a Creative Commons Attribution 4.0 International License, which permits use, sharing, adaptation, distribution and reproduction in any medium or format, as long as you give appropriate credit to the original author(s) and the source, provide a link to the Creative Commons licence, and indicate if changes were made. The images or other third party material in this article are included in the article's Creative Commons licence, unless indicated otherwise in a credit line to the material. If material is not included in the article's Creative Commons licence and your intended use is not permitted by statutory regulation or exceeds the permitted use, you will need to obtain permission directly from the copyright holder. To view a copy of this licence, visit http://creativecommons.org/licenses/by/4.0/. The Creative Commons Public Domain Dedication waiver (http://creativecommons.org/publicdomain/zero/1.0/) applies to the data made available in this article, unless otherwise stated in a credit line to the data. 


\section{Background}

Rifampicin-resistant and multidrug-resistant tuberculosis (RR/MDR-TB) threatens to impede global tuberculosis (TB) control efforts and progress towards the World Health Organization End TB targets [1], with approximately half a million incident cases in 2018 [2]. RR/ MDR-TB has worse treatment outcomes than drugsusceptible TB (DS-TB) and imposes a disproportionate cost on health systems and patients $[3,4]$. Further, prolonged multi-agent treatment for RR/MDR-TB may contribute to wider antimicrobial resistance [5]. As such, there is an urgent need for novel interventions to control and prevent RR/MDR-TB.

Prophylactic TB vaccine candidates progressed considerably through the development pipeline in 2018-2019. Results from the $\mathrm{M} 72 / \mathrm{ASO}_{\mathrm{E}}$ [6] and BCG revaccination [7] trials suggest possible vaccine efficacy of $50 \%$ and $46 \%$ in Interferon- $\gamma$ release assay (IFNy) + and IFNynegative patients, respectively. These trials did not include RR/MDR-TB endpoints due to its relative rarity.

Mathematical modelling techniques could investigate the potential effect of vaccination on RR/MDR-TB. However, to date, no modelling studies have assessed the epidemiologic impact of novel TB vaccines on RR/ MDR-TB. Furthermore, studies of TB vaccine costeffectiveness have omitted RR/MDR-TB or not modelled RR/MDR-TB dynamically [8, 9].

The global distribution of RR/MDR-TB is heterogenous, with India and China accounting for $27 \%$ and $14 \%$ of all global cases, respectively [2]. High-quality national RR/ MDR-TB burden estimates are derived through large and infrequent drug-resistance surveys; consequently, data to inform drug resistance trends are sparse. In 2017, globally, 3.5\% (95\% CI 2.5-4.7\%) of new and 18\% (95\% CI 6.3$34 \%)$ of previously treated TB cases were estimated to have RR/MDR-TB [10]. Data from China indicate slightly higher rates, with estimates of $7.1 \%$ (95\% CI 5.6-8.7) and $24 \%$ (95\% CI 20-24) RR/MDR-TB among new and previously treated cases. Data from India indicate slightly lower-than-global rates. Estimates from the first national drug-resistance survey, reporting in 2018, place RR/MDRTB among new and previously treated cases at $2.8 \%$ (CI 2.3-3.5) and $11.6 \%$ (10.2-13.2), respectively. Approximately $69 \%$ and $74 \%$ of RR-TB cases are estimated to be MDR-TB (defined as resistance to isoniazid in addition to rifampicin) in India and China, respectively, consistent with the global average of $78 \%$. Despite these similarities, China and India have substantially differing demographics, TB epidemiology and health systems [2, $11,12]$. As such, in this study, we modelled the epidemiologic impact, cost-effectiveness and budget impact of prophylactic vaccination against TB, while dynamically modelling epidemics of DS- and RR/MDR-TB in China and India.

\section{Methods}

\section{Model structure and calibration}

We programmed an age-, treatment history- and drug resistance-stratified compartmental transmission model of TB in R [13], extending previously developed methods $[8,14,15]$. Details of model structure, diagram, equations, calibration, vaccine implementation, demography and health economic analysis are described in Additional file $1[2,7,8,11-14,16-101]$. The model time horizon was 1950-2050.

The model allowed for five states of TB disease: (1) susceptible; (2) latently infected; (3) active disease (both infectious, i.e., bacteriologically sputum-positive, and noninfectious, i.e., bacteriologically sputum-negative, and extra-pulmonary); (4) on-treatment; and (5) recovered from disease, stratified by drug-susceptible/drug-resistant, and treatment history (Fig. S1 in Additional file 1). All states were stratified by vaccination status. Transitions between states represented acquisition of infection, progression to latency or active disease, conversion of noninfectious to infectious active disease, detection of active disease and initiation of treatment, treatment success or failure, reactivation from latency and relapse from recovered states. Misdiagnosis of RR/MDR-TB was assumed to lead to inappropriate initiation of DS-TB treatment and treatment failure. Consistent with empirical data, progression to active disease following re-infection of latent and recovered populations was assumed to occur at a lower rate than naive populations [42]. We assumed that RR/ MDR-TB could develop following drug resistance acquisition in situ while on treatment for DS-TB or following transmission of drug-resistant $M$. tuberculosis. Transmission could occur between drug-resistance strata. We assumed resistance acquisition and RR/MDR-TB treatment began in 1970 .

Neonates entered the model uninfected. We modelled $0-100$ years in 1 -year age groups and applied all-cause mortality to all states, with TB-specific mortality applied to active-disease and on-treatment states. We applied age-assortative contact patterns using empirical data for China [39] and by adapting POLYMOD contact matrices [40] for India.

We obtained prior ranges for natural history parameters from the literature (Additional file 1, section 2.4), including age-stratified ranges where available. We assumed RR/MDR-TB was less than or equally transmissible to DS-TB [28, 29]. We constrained rates of fast progression to active disease, reactivation from latent infection, relapse from recovered state and TB mortality to be greater or equal in children (age $<15$ years) than adults [21,47]; in China, we also constrained these rates to be greater or equal in the elderly (age $>64$ years) than in adults (age 15-64). We applied the opposite constraint to natural cure rate [21, 47]. 


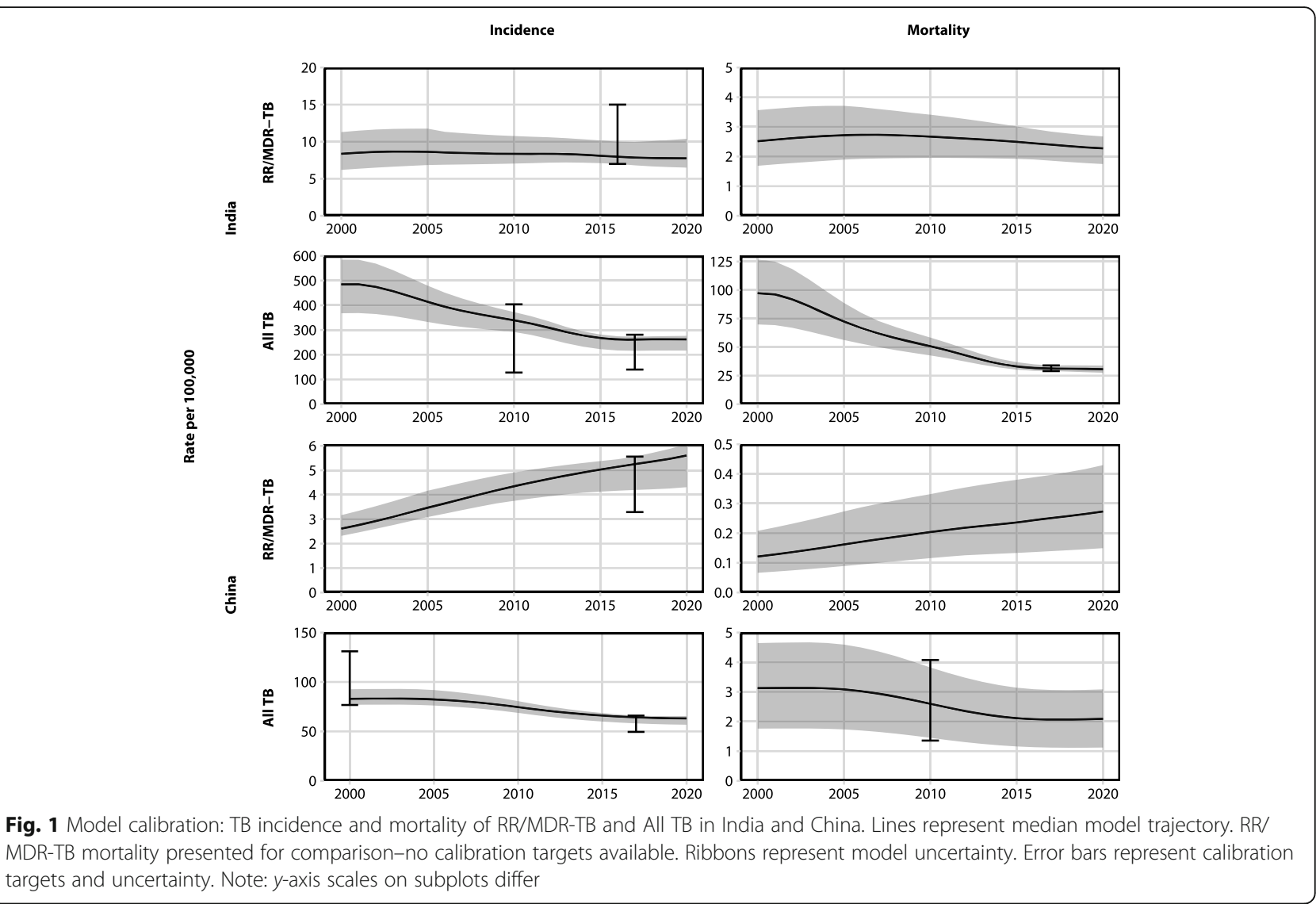

We used country-specific case-detection rates to inform diagnosis and treatment initiation [31] (Additional file 1, section 2.5). RR/MDR-TB was diagnosed through a combined probability of drug-susceptibility testing (determined by country-specific drug-susceptibility testing coverage) and empirical diagnosis (Additional file 1, section 2.5). We based treatment success for DS-TB and RR/ MDR-TB treatment on historical data [31, 58]. In India, we adjusted case-detection and DS-TB treatment success rates for a large private healthcare sector $[2,11,32]$, where we assumed a lower treatment success rate for DS-TB and unsuccessful treatment of RR/MDR-TB [Rao, R., personal communication]. Beyond 2018, we maintained constant rates of treatment initiation, drug-susceptibility testing coverage and treatment success.

We calibrated the model to historical rates of all $\mathrm{TB}$ prevalence, incidence, notification and mortality $[2,34$, $35,69], \mathrm{RR} / \mathrm{MDR}-\mathrm{TB}$ incidence rate and percentage RR/ MDR-TB among notifications (stratified by treatment history) in each country. In India, we fitted to total RR/ MDR-TB treatment initiations in the public sector. In China, we constrained the number of RR/MDR-TB treatments contributing to cost-effectiveness calculations to the number of laboratory-confirmed RR/MDR-TB treatment initiations reported by China Centres for
Disease Control [31]. Where data allowed, we stratified calibration targets by age group $(<15,15-64$ and $\geq 65$ years in China, and $<15$ and $\geq 15$ years in India).

Model calibration used Approximate Bayesian Computation $(\mathrm{ABC})$ rejection-sampling process and $\mathrm{ABC}$ Markov chain Monte Carlo sampling. We randomly subsampled 1000 fully calibrated parameter sets to generate model runs, whose median trajectory we used as an estimate of central tendency and whose maximum and minimum trajectories represent uncertainty intervals.

\section{Vaccine implementation}

We simulated vaccine introduction in 2027 for each country and estimated vaccine impact for $2027-2050$ by comparison to the corresponding unvaccinated baseline model runs.

We modelled two simultaneous vaccination strategies: routine annual vaccination and mass vaccination campaigns. We assumed routine annual vaccine administration to 9-year-olds, co-delivered with human papillomavirus (HPV) vaccine, with coverage of $80 \%$, based on HPV vaccine coverage in South Africa and secondary school enrolment ratios in China and India. Mass campaigns were delivered 10 -yearly to ages $\geq 10$ at $70 \%$ coverage based on 
existing data for Menafrivac mass campaigns delivered to 1-29-year-olds. We delivered vaccination to populations in the model who had neither active disease or nor were receiving treatment, assuming no pre-immunisation testing for latent TB [73]. No other targeting or eligibility criteria were applied. We assumed a prevention of disease vaccine, priced at US\$10, conferring 50\% efficacy for 10 years, with vaccine efficacy in individuals with a previous history of $M$. tb infection ("post-infection"; PSI) or irrespective of infection ("pre- and post-infection"; P\&PI). Vaccine was modelled as a reduction in the rates of progression to disease following infection, reactivation from latency and relapse from the recovered state. The reduction was proportional to vaccine efficacy. A lower burden of active disease further depressed the force of infection, leading to lower rates of $M$. tb transmission. We modelled vaccination as equally protective against DS-TB and RR/MDR-TB and in those with or without previous treatment history for either. In addition to the direct prevention of disease mechanism (above), vaccine reduced RR/ MDR-TB burden indirectly by reducing DS-TB burden. Reduced DS-TB burden translated to reduced total patient-time on treatment for DS-TB, leading to lower drug-resistance acquisition. Vaccine waning was implemented as instantaneous at the end of duration of protection. We did not explicitly represent existing Bacillus Calmette-Guérin (BCG) immunisation programmes as we assumed protection conferred by BCG to be reflected in calibration targets.

As measures of vaccine impact, we calculated percentage reduction in incidence rate and mortality rate, in vaccine scenarios in 2030 and 2050, compared to baseline and corresponding number of cumulative averted TB cases and deaths.

\section{Cost, cost-effectiveness and budget impact}

We estimated costs from a public sector perspective using an ingredients approach. Unit cost assumptions, estimates and full references are provided in Additional file 1 , section 5 . Briefly, we calculated costs incurred by the vaccine and TB programmes.

We estimated three categories of intervention (vaccine programme) costs: vaccine, delivery and programme costs. We modelled vaccines priced at US\$10 as the base case. We estimated US\$1.13-2.40 (routine) or US\$1.202.47 (mass campaign) delivery cost per person vaccinated in India, and US\$1.60-2.80 for both routine and mass campaign delivery cost in China. Programme costs included mass campaign organisation and management, which we estimated from the literature at US $\$ 25,374,949$ per campaign in India, and US\$16,133.10 per 10,000 persons vaccinated per campaign in China.

TB programme costs represented service costs for TB diagnosis (including drug-susceptibility testing) and treatment (Additional file 1, section 5.1). For India, we added costs representing nutritional support payments to patients and government incentives to improve TB case notification in the private healthcare sector. We inflated historic cost-data to 2018 values where appropriate.

We calculated incremental costs of vaccination as the difference in total costs predicted between vaccine and corresponding baseline scenario.

Using standardised outputs from the model (deaths due to DS and RR/MDR-TB by age and year and time spent with active DS and RR/MDR-TB disease), we calculated total (DS-TB and RR/MDR-TB) disabilityadjusted life years (DALYs) averted by vaccination. We applied disability weights per the Global Burden of Disease study [95] and life expectancy from the UN World Population Prospects [38]. Future costs and DALYs averted were discounted at $3 \%$.

We calculated incremental cost-effectiveness ratios (ICERs) for the 1000 vaccine runs and constructed costeffectiveness acceptability curves for each vaccine profile through a probabilistic sensitivity analysis. Input costs were sampled from their corresponding uncertainty ranges and attached to each vaccine run. We report the proportion of ICERs which fall below three illustrative thresholds per country: 1-times 2018 World Bank gross domestic product (GDP) per capita and the lowest and highest healthcare opportunity cost (HCOC) thresholds estimated by Ochalek et al. [101].

We present budget impact for immunisation and TB programmes separately. For the immunisation programme, we present total costs incurred by instantaneous deployment of vaccine. For the TB programme, we present annual total costs for programmatic management of TB. Health economic analysis was undertaken in line with the Consolidated Health Economic Evaluation Reporting Standards [102] (Additional file 2).

\section{Scenario analysis}

We conducted scenario analyses in two areas: product related, pertaining to vaccine characteristics and cost, and baseline related, pertaining to uncertainty in programmatic (non-vaccine) TB management and associated future health system investments.

Under product-related scenario analysis, we modelled vaccines with $30 \%, 70 \%$ and $90 \%$ efficacy, 5-years duration of protection, $30 \%$ mass campaign coverage and a vaccine price of US\$30. There are no vaccine candidates in advanced development that prevent disease solely in uninfected (i.e., pre-infection) populations. Therefore, we present vaccines effective pre-infection (PRI) vaccines as a scenario analysis.

For baseline-related uncertainty, to capture the impact of vaccination in the context of uncertainty in future 
health system investments, and in contrast to the baseline scenario with no programmatic change after 2018, we defined an alternative "Policy" scenario, representing a scaled-up programmatic TB management for each country (Additional file 1, section 2.6).

For China, the Policy scenario was informed by country expert opinion. It included linearly scaling up drugsusceptibility testing coverage to $90 \%$ by 2036 and introduction of a standard 9-month RR/MDR-TB treatment regimen (with the same treatment success rate), linearly increasing this to $40 \%$ of all second-line therapy by 2036 [Li, R., personal communication].

For India, the National Strategic Plan of the Indian Revised National Tuberculosis Control Programme [36] informed the Policy scenario, defined as (1) increased case detection rate (combined across private and public sectors) to $85 \%$, (2) increased drug-susceptibility testing coverage among public sector notifications to $100 \%$ and (3) increased proportion of notifications originating from the private sector to 35\%, all by 2025 .

\section{Model uncertainty}

The final estimates of uncertainty in the results reflect a combination of epidemiologic input parameter uncertainty (delineated through sampling during calibration) and cost input uncertainty (incorporated through sampling during the probabilistic sensitivity analysis for cost-effectiveness analysis).

\section{Role of the funder}

The study funder was involved in developing the research question and commented on the draft manuscript, but had no role in study design, data collection, analysis, interpretation, nor writing the initial draft. The corresponding author had full access to all study data and materials and had final responsibility for the decision to submit for publication.

\section{Results \\ Calibration}

We calibrated to all TB prevalence, incidence, notification and mortality, and to RR/MDR-TB specific rates of incidence, proportion among all TB notifications (stratified by treatment history) and number of treatment initiations (Fig. 1; further details in Additional file 1, section $6)$. The model predicted a RR/MDR-TB incidence and mortality rate per 100,000 in 2018 of 7.8 (UI: $6.7-10.1$ ) and 2.4 (UI: 1.8-2.8) in India, respectively, and 5.4 (UI: 4.2-5.7) and 0.3 (UI: $0.1-0.4$ ) in China, respectively (Fig. 1, rows 1 and 3). Baseline epidemiologic projections (without vaccine) are provided in Additional file 1, section 6. The model predicted that RR/MDR-TB incidence in China was predominantly driven by infection of susceptible (naive) individuals. In contrast, RR/MDR-TB incidence in India was driven by equal proportions of new infection of susceptible and re-infection of latently infected individuals (Additional file 1, section 7.2).

\section{Epidemiologic impact}

A summary of the epidemiologic impact of both P\&PI and PSI vaccines is presented in Figs. 2 and 3 and Tables 1 and 2 .

In India, we found the P\&PI vaccine reduced the RR/ MDR-TB incidence rate in 2050 by $72 \%$ (UI: $65-77$ ), corresponding to 2.0 (UI: 1.4-4.1) million cases averted (Table 1, Fig. 2). The PSI vaccine reduced the RR/MDRTB incidence rate in 2050 by $47 \%$ (UI: 37-58), corresponding to 1.3 (UI: 0.9-2.6) million cases averted (Table 1, Fig. 2). The P\&PI and PSI vaccines reduced all TB incidence rate in 2050 by $67 \%$ (UI: $59-71$ ) and $44 \%$ (UI: 39-49), respectively (Table 1, Fig. 3).

In China, we found the P\&PI vaccine reduced the RR/ MDR-TB incidence rate in 2050 by $73 \%$ (UI: 66-76), corresponding to 2.1 (UI: 1.1-2.7) million cases averted (Table 2, Fig. 2). The PSI vaccine reduced the RR/MDRTB incidence rate in 2050 by 29\% (UI: 27-31), corresponding to 0.7 (UI: 0.5-0.9) million cases averted (Table 2, Fig. 2). The P\&PI and PSI vaccines reduced all TB incidence rate in 2050 by $56 \%$ (UI: $53-59$ ) and $37 \%$ (UI: 35-38), respectively (Table 2, Fig. 3).

We found a similar relative effect of P\&PI vaccines compared to PSI vaccines on RR/MDR-TB mortality rate and deaths averted, and on all TB mortality rate, and cases and deaths averted (Tables 1 and 2).

\section{Averted treatment}

In India, P\&PI and PSI vaccines were predicted to avert 0.8 (UI: 0.5-1.4) million and 0.5 (UI: 0.3-1.1) million RR/MDR-TB treatment regimens (not shown). In China, the model predicted the P\&PI and PSI vaccines would avert 1.0 (UI: $0.6-1.3$ ) million and 0.3 (UI: 0.2-0.4) million RR/MDR-TB treatment regimens, respectively (not shown).

\section{Cost-effectiveness}

In India, in a discounted analysis, we estimated ICERs of \$151 (UI: 82-210) and \$284 (UI: 189-389) for P\&PI and PSI vaccines priced at USD 10, respectively (Fig. 4), over 2027-2050. The P\&PI vaccine was predicted to be costeffective in $100 \%$ of model runs at the 1-times GDP, and upper and lower HCOC thresholds. The PSI vaccine was predicted to be cost-effective in $100 \%, 99 \%$ and $27 \%$ of runs at the 1-times GDP, upper HCOC and lower HCOC thresholds, respectively.

In China, in a discounted analysis, we estimated ICERs of $\$ 3663$ (UI: 2763-4754) and \$6059 (UI: 4591-7749) for P\&PI and PSI vaccines priced at USD 10, respectively (Fig. 4), over 2027-2050. The P\&PI vaccine was 


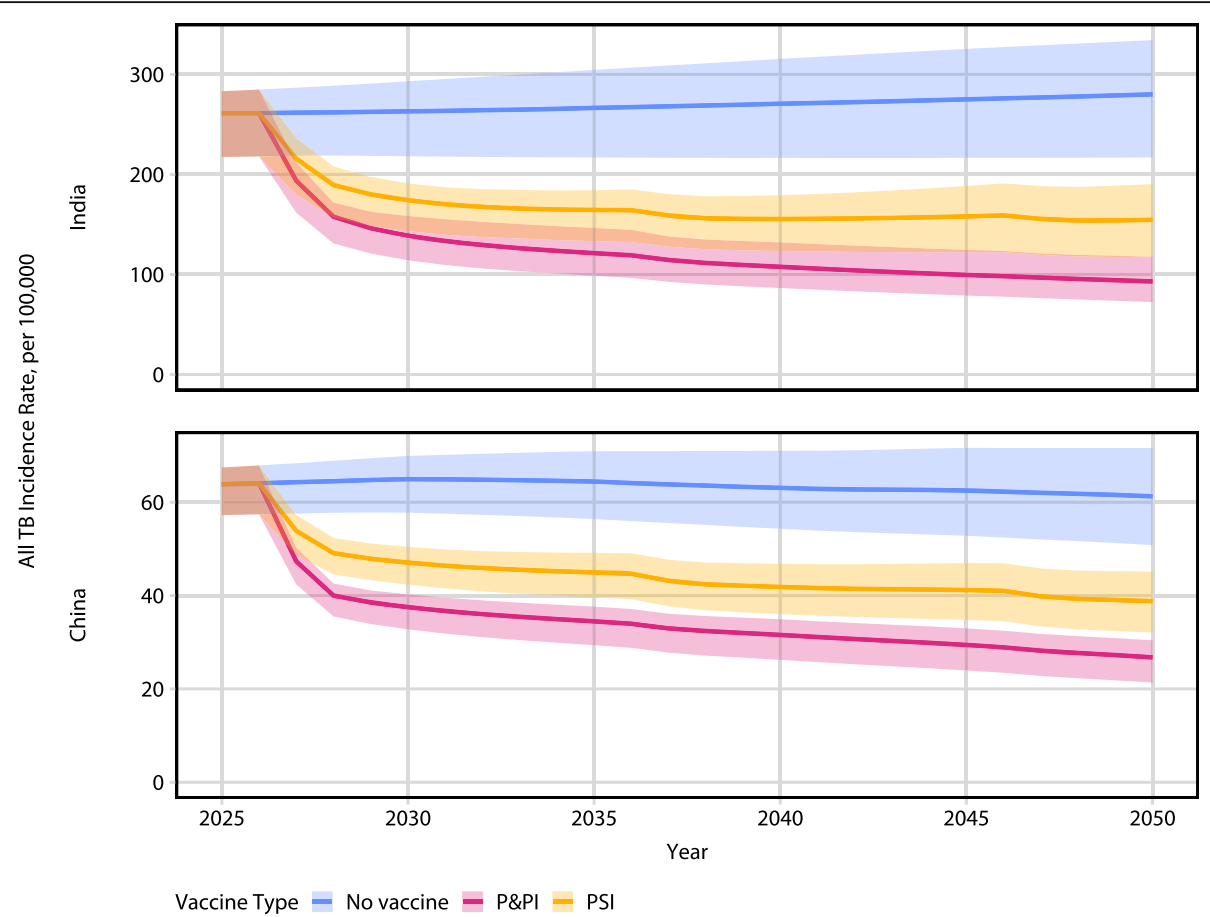

Fig. 2 Incidence rate reduction of all TB by 50\% efficacy, 10-year duration of protection pre- and post-infection efficacy (P\&PI) and post-infection efficacy (PSI) vaccines in India (top) and China (bottom). Lines represent median model incidence rate; ribbons represent model uncertainty. Vaccine is introduced in 2027. Note: $y$-axis scales on subplots differ

predicted to be cost-effective in $100 \%$ of runs at the 1 times GDP threshold and upper HCOC threshold, and $49 \%$ of runs at the lower HCOC threshold. The PSI vaccine was cost-effective at $100 \%$ and $21 \%$ of runs at the 1 times GDP and upper HCOC threshold, but not costeffective at the lower HCOC threshold.

\section{Budget impact}

The total undiscounted costs for instantly deployed mass campaigns and routine annual vaccination for a $50 \%$ efficacy P\&PI vaccine providing 10 years of protection and total savings in the TB programme over 2027-2050 are presented in Table 3. Immunisation programme costs were similar for a PSI vaccine priced at US\$10 in India and China (Additional file 1, section 9) but with lower TB programme savings. The total annual expenditure by the National Tuberculosis Programmes for India and China over 2027-2050 is shown in Fig. 5.

\section{Scenario analyses}

We found increasing vaccine efficacy increased percent incidence rate reduction, cases averted, percent mortality rate reduction, deaths averted in both RR/MDR-TB and all TB, and averted DS-TB and RR/MRD-TB treatment regimens. Reduced duration of protection to 5 years or reduced vaccine efficacy (Additional file 1, sections 7.3 and
7.4) had the opposite effect. PRI vaccines had a comparable or lower impact than PSI vaccines in all cases except for RR/MDR-TB in China, where PRI effect was greater than PSI (Additional file 1, sections 7.2 and 7.3).

We found vaccines (of all types, efficacies and durations of protection) affected a similar per cent incidence rate reduction and per cent mortality rate reduction in both all TB and RR/MDR-TB, in both India and China, in the Policy scenario as compared to the unchanged baseline. Fewer cases and deaths were averted in the Policy scenario, leading to a lower absolute impact of vaccination. ICERs for vaccination were higher in undiscounted analyses, with a vaccine priced at US\$30, and in the Policy scenario for each country (Additional file 1, section 8).

\section{Discussion}

We estimate that the introduction of new TB vaccines in India and China in 2027 might substantially reduce RR/ MDR-TB burden by 2050. A pre- and post-infection vaccine (effective in all individuals, irrespective of their infection status by $M$. tb) was projected to reduce RR/ MDR-TB incidence rate by approximately $70 \%$ in both India and China if delivered annually to 9-year-olds and every 10 years to ages 10 and above. A post-infection vaccine (effective only in individuals with latent $M$. tb infection or who have recovered from $\mathrm{TB}$ ) was projected 


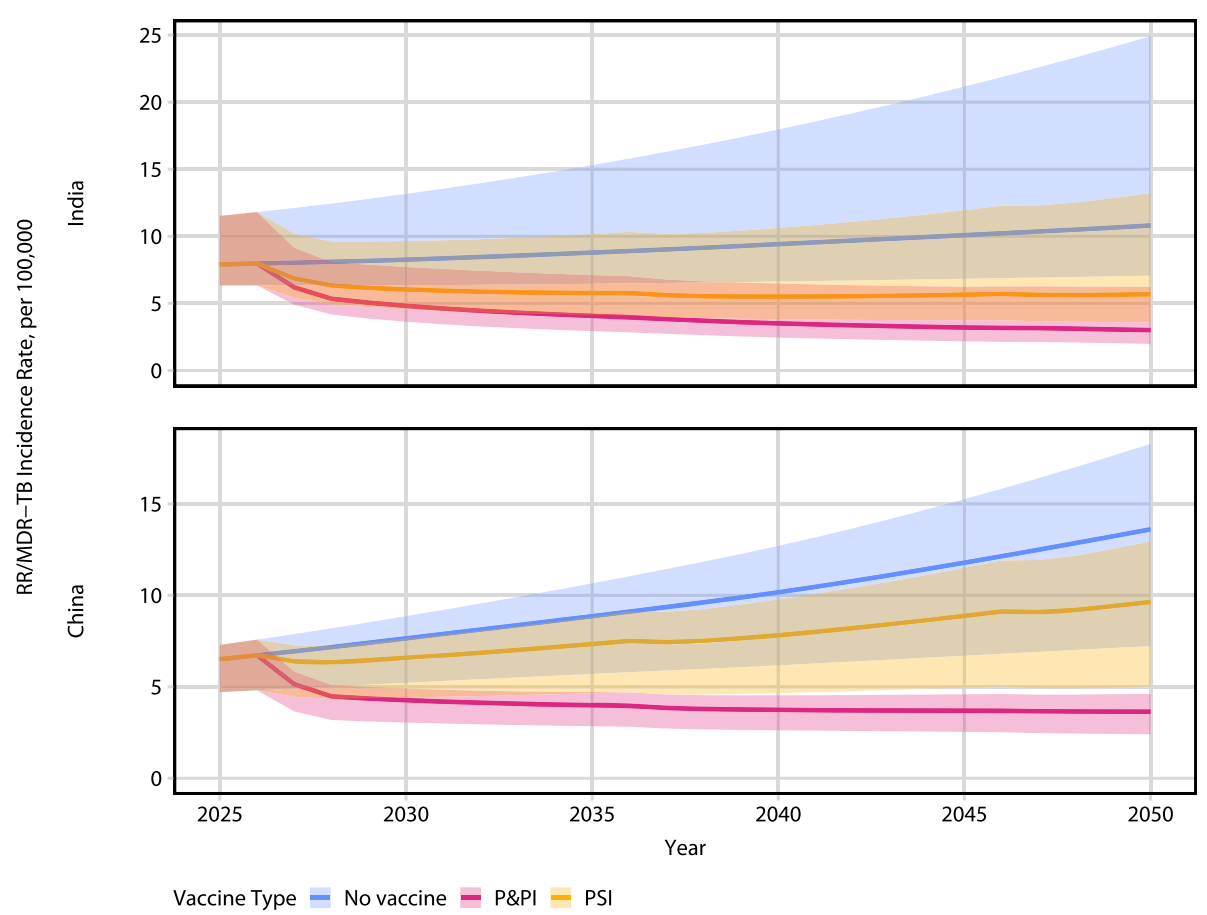

Fig. 3 Incidence rate reduction of RR/MDR-TB by 50\% efficacy, 10-year duration of protection pre- and post-infection efficacy (P\&PI) and postinfection efficacy (PSI) vaccines in India (top) and China (bottom). Lines represent median model incidence rate; ribbons represent model uncertainty. Vaccine is introduced in 2027

to impart lower but still substantial reductions of approximately $50 \%$ and $30 \% \mathrm{RR} / \mathrm{MDR}-\mathrm{TB}$ incidence rate reduction in India and China, respectively.

P\&PI vaccines priced at US $\$ 10$ were highly likely to be cost-effective in India and China at the 1-times GDP and upper HCOC thresholds. In India, P\&PI vaccines were also likely to be cost-effective at the lower HCOC threshold. While we found PSI vaccines to be less cost-effective than P\&PI vaccines in general, a PSI vaccine priced at US $\$ 10$ remained highly likely to be cost-effective at the 1-times GDP threshold in both India and China and at the upper HCOC threshold in India. In both countries, vaccination was projected to avert approximately 1 million RR/MDR-TB regimens by 2050.

We attributed the greater PSI vaccine impact on RR/ MDR-TB in India than China, to the proportionally greater rate of re-infection and fast progression of latent RR/MDR-TB (which is avertible through post-infection vaccine efficacy) at baseline (Additional file 1, section 7.2). Moreover, in China, the RR/MDR-TB epidemicdriven by new infections among susceptible (naive)

Table 1 India-Epidemiologic impact for 50\% efficacy, 10-year duration of protection vaccines. Estimates are median (uncertainty interval) values. Incidence and mortality rate reductions compare annual values of vaccine vs baseline in 2030 and 2050 . Cases and deaths averted are cumulative over 2027-2030 and 2027-2050

\begin{tabular}{|c|c|c|c|c|c|}
\hline \multirow[b]{2}{*}{ Resistance status } & \multirow[b]{2}{*}{ Outcome } & \multicolumn{2}{|c|}{ Pre- and post-infection vaccine } & \multicolumn{2}{|c|}{ Post-infection vaccine } \\
\hline & & 2030 & 2050 & 2030 & 2050 \\
\hline \multirow[t]{4}{*}{ RR/MDR-TB } & $\%$ Incidence rate reduction in year & $42 \%(37-45)$ & $72 \%(65-77)$ & $27 \%(20-34)$ & $47 \%(37-58)$ \\
\hline & $\%$ Mortality rate reduction in year & $20 \%(15-24)$ & $69 \%(60-75)$ & $13 \%(8-19)$ & $45 \%(33-55)$ \\
\hline & Cumulative cases averted, millions & $0.2(0.1-0.3)$ & $2.0(1.4-4.1)$ & $0.1(0.1-0.2)$ & $1.3(0.9-2.6)$ \\
\hline & Cumulative deaths averted, millions & $0.015(0.008-0.02)$ & $0.4(0.3-0.7)$ & $0.009(0.004-0.015)$ & $0.3(0.2-0.4)$ \\
\hline \multirow[t]{4}{*}{ All TB } & $\%$ Incidence rate reduction in year & $47 \%(41-51)$ & $67 \%(59-71)$ & $34 \%(28-39)$ & $44 \%(39-49)$ \\
\hline & $\%$ Mortality rate reduction in year & $36 \%(28-41)$ & $66 \%(59-71)$ & $25 \%(18-31)$ & $44 \%(38-49)$ \\
\hline & Cumulative cases averted, millions & $6.1(5.0-7.0)$ & $57.1(45.9-70.0)$ & $4.3(3.3-5.2)$ & $39.6(31.4-48.2)$ \\
\hline & Cumulative deaths averted, millions & $0.4(0.3-0.5)$ & $5.9(4.7-7.9)$ & $0.3(0.2-0.3)$ & $4.1(3.0-5.3)$ \\
\hline
\end{tabular}


Table 2 China-Epidemiologic impact for 50\% efficacy, 10-year duration of protection vaccines. Estimates are median (uncertainty interval) values. Incidence and mortality rate reductions compare annual values of vaccine vs baseline in 2030 and 2050 . Cases and deaths averted are cumulative over 2027-2030 and 2027-2050

\begin{tabular}{|c|c|c|c|c|c|}
\hline \multirow[b]{2}{*}{ Resistance status } & \multirow[b]{2}{*}{ Outcome } & \multicolumn{2}{|c|}{ Pre- and post-infection vaccine } & \multicolumn{2}{|c|}{ Post-infection vaccine } \\
\hline & & 2030 & 2050 & 2030 & 2050 \\
\hline \multirow[t]{4}{*}{ RR/MDR-TB } & $\%$ Incidence rate reduction in year & $44 \%(42-46)$ & $73 \%(66-76)$ & $14 \%(13-16)$ & $29 \%(27-31)$ \\
\hline & $\%$ Mortality rate reduction in year & $22 \%(18-24)$ & $67 \%(59-72)$ & $8 \%(6-10)$ & $28 \%(25-30)$ \\
\hline & Cumulative cases averted, millions & $0.2(0.1-0.2)$ & $2.1(1.1-2.7)$ & $0.05(0.04-0.06)$ & $0.7(0.5-0.9)$ \\
\hline & Cumulative deaths averted, millions & $0.003(0.001-0.005)$ & $0.1(0.0-0.2)$ & $0.001(0.001-0.002)$ & $0.04(0.02-0.06)$ \\
\hline \multirow[t]{4}{*}{ All TB } & $\%$ Incidence rate reduction in year & $42 \%(40-44)$ & $56 \%(53-59)$ & $28 \%(26-29)$ & $37 \%(35-38)$ \\
\hline & $\%$ Mortality rate reduction in year & $29 \%(26-32)$ & $53 \%(48-58)$ & $21 \%(18-24)$ & $35 \%(33-36)$ \\
\hline & Cumulative cases averted, millions & $1.4(1.2-1.5)$ & $10.5(8.9-12.0)$ & $0.9(0.8-1.0)$ & $6.9(5.9-7.8)$ \\
\hline & Cumulative deaths averted, millions & $0.02(0.01-0.04)$ & $0.4(0.2-0.5)$ & $0.02(0.01-0.03)$ & $0.3(0.1-0.4)$ \\
\hline
\end{tabular}

individuals - was more impacted by PRI than PSI vaccine efficacy (Additional file 1, section 7.2).

We found that vaccination averted a substantially higher absolute number of all TB cases and deaths in India than China. This reflected higher TB incidence and substantially higher TB mortality at baseline in India than China. The greater averted burden translated to greater averted life-years otherwise lost to TB; thus, despite lower TB management costs, for all vaccine profiles, ICERs in India were lower than in China. Correspondingly, savings in the TB programme were greater in India than China and reflect an underestimate for both countries, as vaccinemediated protection and the dynamic impact of vaccination on the TB epidemic would continue to suppress TB burden beyond the model time horizon.

This study had several limitations pertaining to (1) model parameterisation and structure, (2) baseline scenarios and (3) vaccine implementation, which we consider in turn.

Data to substantiate natural history parameters for RR/MDR-TB were sparse and heterogeneous [28, 103,
104]. We assumed RR/MDR-TB transmissibility was equal to or lower than DS-TB $[28,29]$ and sampled from wide parameter priors. In the absence of evidence or a priori reasoning for differing values, we assumed other RR/MDR-TB and DS-TB parameters had the same values. As new empirical evidence arises, our predictions and estimates can be updated, but it is currently difficult to identify their direction of bias. Further, we maintained constant country-specific contact patterns over the model time horizon between DS and RR/MDR-TB. If individuals with RR/MDR-TB were to mix with one another preferentially, our results may overestimate vaccine impact.

To test our baseline assumptions of post-2018 constant case detection rates and drug-sensitivity testing coverage, we implemented a contrasting scaled up programmatic management scenario based on country-specific national policy. Our conclusions regarding relative vaccine impact remained robust to programmatic scale-up. However, we did not change RR/MDR-TB treatment success rate nor introduce a theoretical future highly effective diagnostic

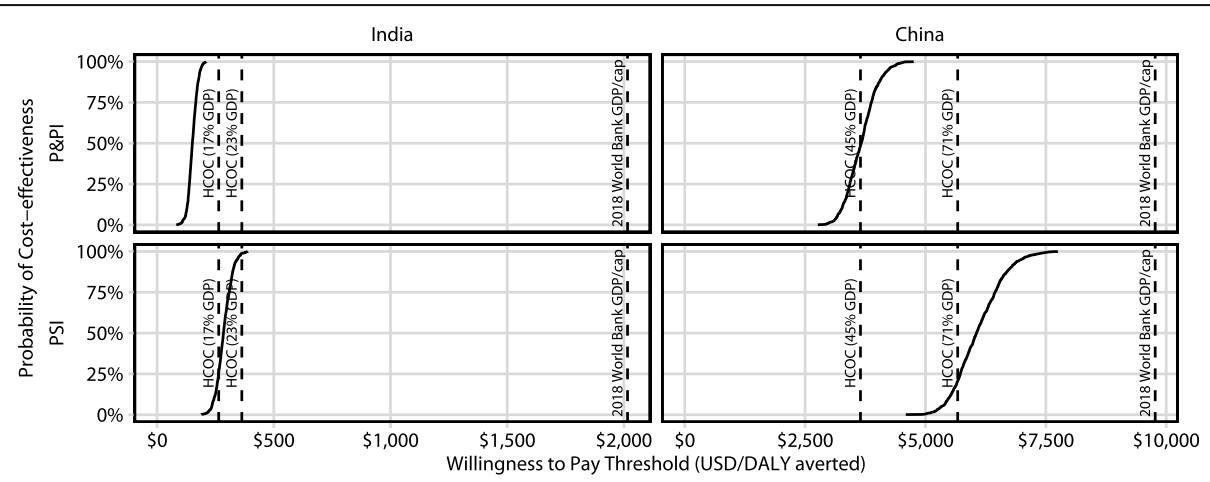

Fig. 4 Cost-effectiveness acceptability curves. Vertical axis shows the probability that 50\% efficacy, 10-year duration of protection pre-and postinfection (P\&Pl; top) and post-infection (PSl; bottom) vaccines are cost-effective at or below a given willingness to pay value (horizontal axis), in India (left) and China (right). Reference lines are 2018 World Bank GDP and upper and lower health-care opportunity-cost thresholds. Note: $x$-axis scales differ between subplots 
Table 3 Estimated cumulative total cost of vaccine programmes and cumulative TB programme savings over 20272050. Costs are presented for a 50\% efficacy P\&PI vaccine providing 10-years of protection. All costs are undiscounted and in billions USD

\begin{tabular}{lll}
\hline & Type & Amount \\
\hline India & Routine vaccination costs & $\$ 5.2(4.9-5.4)$ \\
& Mass vaccination costs & $\$ 33.4(31.9-34.6)$ \\
& All vaccination programme costs & $\$ 38.6(37.1-39.9)$ \\
& TB Programme savings & $\$ 19.4(13.0-27.2)$ \\
China & Routine vaccination costs & $\$ 3.4(3.2-3.5)$ \\
& Mass vaccination costs & $\$ 38.1(36.4-39.2)$ \\
& All vaccination programme costs & $\$ 41.5(39.8-42.6)$ \\
& TB programme savings & $\$ 5.2(3.9-6.8)$ \\
\hline
\end{tabular}

technology, either of which may reduce vaccine impact estimates. In India, we assumed the private health sector did not treat RR/MDR-TB successfully, based on in-country expert opinion. Should overall treatment success improve because of a larger private sector engagement effort, relative vaccine impact might remain stable, but absolute impacts may be reduced. We cannot speculate on the impact on cost-effectiveness, as this would depend on the specific mechanism of increased private sector engagement. Should the strategic focus of the Indian National Tuberculosis Programme change to include improved RR/MDR$\mathrm{TB}$ treatment in the private healthcare sector, a new baseline scenario could be modelled to estimate the potential effect on vaccine impact. In China, we assumed the number of RR/MDR-TB treatment initiations contributing to programme costs was equal to the number starting treatment as reported by the Chinese Centre for Disease Control and Prevention (CDC). However, the averted number of treatments estimate applies to all RR/MDR-TB treatment-both CDC and non-CDC. As the total RR/ MDR-TB treatment volume is unconstrained, our result of averted treatment may be an overestimate. We confined our health-economic analysis to a public sector healthcare perspective. TB-related costs to patients, including indirect costs from seeking healthcare and productivity losses, can be substantial [3]; these costs are not factored into our cost-effectiveness analysis. However, our analysis does include TB programme costs related to patient and private sector support: in India, we included nutritional support payments to TB patients and payments to incentivise private sector healthcare providers.

We implemented vaccine waning as an instantaneous loss of efficacy. If empirical data suggested a different waning shape, our estimates may over or underestimate the impact. We did not investigate vaccine targeting (e.g. by age, or by RR/MDR-TB risk group); targeting could improve cost-effectiveness estimates but reduce overall impact. We assumed population-wide mass campaigns were deployed instantaneously, with simultaneously applied costs, instead of through phased multi-year

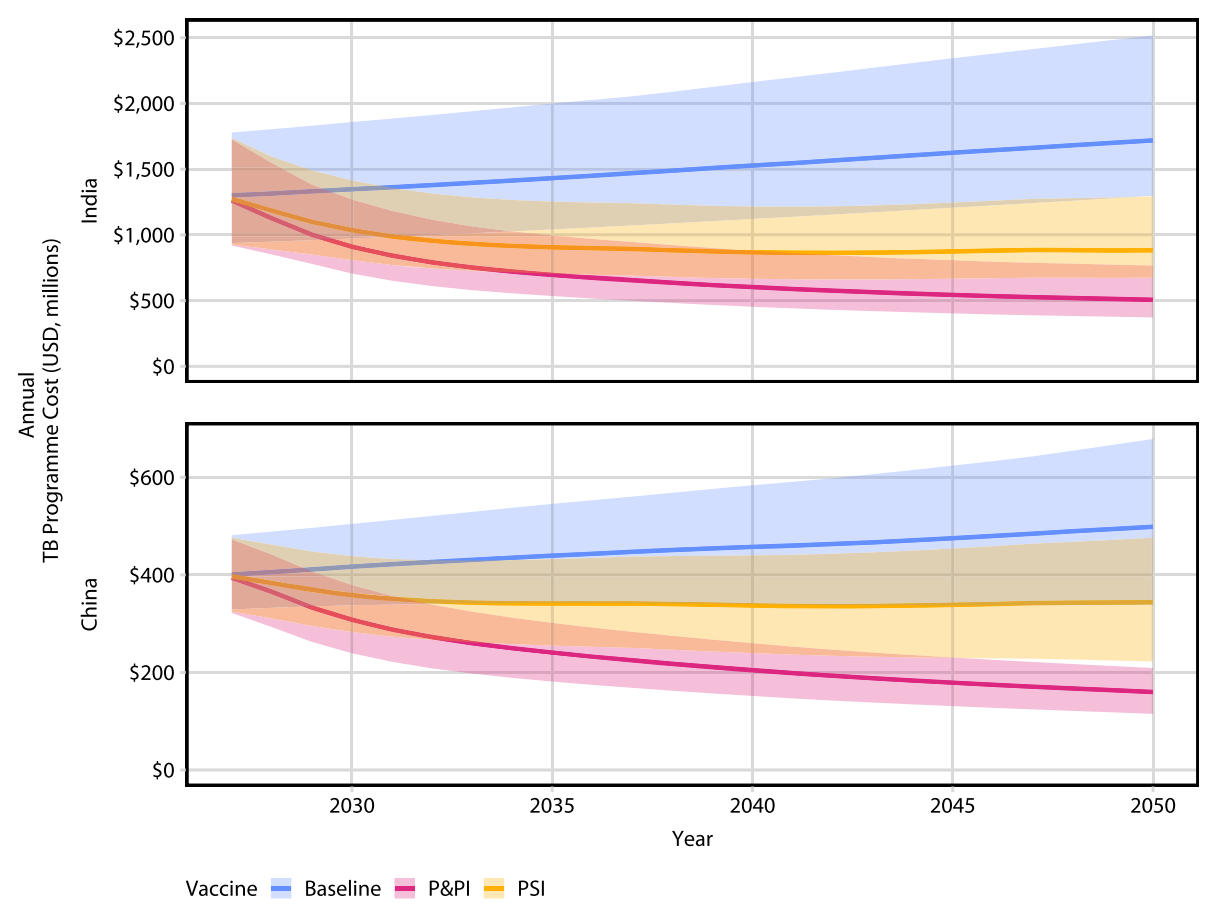

Fig. 5 Budget impact analysis. Annual expenditure by the national TB programmes TB-related costs. Vertical axis represents annual expenditure, in millions USD, by the national TB programme, with and without vaccine, in India (top) and China (bottom). Lines represent median modelled expenditure; ribbons represent model uncertainty 
campaigns. These assumptions have one main consequence: vaccine-associated costs, which were calculated assuming that countries do not need additional capacity to deliver these campaigns, are an underestimate. However, as the benefits of such campaigns were also realised from the start, the ICERs may not be an underestimate. Finally, while we capture the cost-savings due to averted RR/MDR-TB treatment, the positive externalities this affords through a reduced contribution to antimicrobial resistance are not included in the cost-effectiveness analysis. We assumed a US $\$ 10$ price per vaccine course and vaccine introduction in 2027. Should vaccine price decline over time, this might increase the probability of cost-effectiveness at the low HCOC threshold in either country or of PSI vaccines in China at the upper HCOC threshold. We speculate that delayed vaccine introduction by a few years would affect vaccine costs and benefits to similar extents and so is unlikely to substantially alter our findings.

Any evaluation of new TB vaccines must be compared to BCG. Neonatal BCG is still offered routinely in India and China [105]. Epidemiologic evidence suggests that BCG prevents severe disease-particularly miliary tuberculosis and tuberculous meningitis-in young children [106]. The effect of neonatal BCG vaccination on pulmonary tuberculosis risk in adults with estimates ranging from none to substantial [107-109]. Current evidence indicates that neonatal BCG vaccination will be inadequate to end transmission of $\mathrm{M}$. tb among adults, which is a prerequisite for global TB elimination. In contrast, we suggest that adolescent and adult vaccinationwith efficacy similar to late-stage vaccine candidate $\mathrm{M} 72 / \mathrm{AS} 01_{\mathrm{E}}$ - which prevents pulmonary TB disease may be a useful contributor towards this goal.

Previous estimates of TB vaccine cost-effectiveness either omit MDR-TB or do not model MDR-TB dynamically $[8,9]$. This is the first study to dynamically model the impact of potential novel vaccines on MDR-TB. We modelled both the de novo acquisition of drugresistance and transmission of drug-resistant $M$. tuberculosis. We also developed a country-specific cost model and estimated the cost-effectiveness of these vaccines. Consequently, our ICER estimates incorporated both the direct impact of vaccination on RR/MDR-TB and indirect effects due to reduced transmission. In India, we also adjusted for differential treatment by the private sector.

\section{Conclusions}

Novel TB vaccination is likely to substantially reduce the future burden of RR/MDR-TB, while averting the need for RR/MDR-TB treatment. Vaccination may be costeffective, but this depends on the local context and specific characteristics of the vaccine. There is an urgent need for new TB vaccines to prevent disease and for further investment in and acceleration of development of such vaccines to progress towards global TB elimination goals. As development of such vaccines continues, decision-makers should consider their potential role in national tuberculosis programmes and in wider antimicrobial resistance control efforts.

\section{Supplementary information}

The online version contains supplementary material available at https://doi. org/10.1186/s12916-021-01932-7.

Additional file 1: Technical Appendix. Figure S1 Model diagram. S2 Case Detection and Treatment Success Rates. S3 Demographic ModelIndia and China. S4 Posterior distributions of sampled parameters-India. S5 Posterior distributions of sampled parameters-India (contd). S6 Posterior distributions of sampled parameters-China. $\mathbf{5 7}$ Posterior distributions of sampled parameters-China (contd). $\mathbf{S 8}$ Calibration Results-All Tuberculosis in India. S9 Calibration Results-RR/MDR-TB in India. S10 Baseline (no vaccine) projections-India. S11 Calibration Results-Prevalence and Incidence of All TB in China. S12 Calibration Results-Notifications and Mortality of All TB in China. $\mathbf{S 1 3}$ Calibration Results - RR/MDR-TB in China. $\mathbf{S 1 4}$ Baseline (no vaccine) projectionsChina. S15 Latent tuberculosis infection. S16 Incident tuberculosis, disaggregated by incidence source. $\mathbf{S 1 7}$ Incidence Rate Reduction in India. S18 Mortality Rate Reduction in India. S19 Incidence Rate Reduction in China. S20 Mortality Rate Reduction in China. S21 RR/MDRTB Cases Averted in India by 2030 and 2050. S22 RR/MDR-TB Deaths Averted in India by 2030 and 2050. S23 All TB Cases Averted in India by 2030 and 2050. S24 All TB Deaths Averted in India by 2030 and 2050. S25 RR/MDR-TB Cases Averted in China by 2030 and 2050. S26 RR/MDRTB Deaths Averted in China by 2030 and 2050. S27 All TB Cases Averted in China by 2030 and 2050, S28 All TB Deaths Averted in China by 2030 and 2050. S29 RR/MDR-TB Treatment Regimens Averted by 2030 \& 2050 in India. S30 DS-TB Treatment Regimens Averted by 2030 \& 2050 in India. S31 RR/MDR-TB Treatment Regimens Averted by 2030 \& 2050 in China. S32 DS-TB Treatment Regimens Averted by 2030 \& 2050 in China. S33 ICER for vaccination in India at USD 10 per vaccine. S34 ICER for vaccination in India at USD 30 per vaccine. S35 ICER for vaccination in China at USD 10 per vaccine. S36 ICER for vaccination in China at USD 30 per vaccine. $\mathbf{S 3 7}$ ICER for vaccination in China at USD 10 per vaccine. S38 ICER for vaccination in China at USD 30 per vaccine. S39 ICER for vaccination in India at USD 10 per vaccine and 30\% mass campaign coverage. $\mathbf{S 4 0}$ ICER for vaccination in China at USD 10 per vaccine and 30\% mass campaign coverage. Tables S1 Model equations—symbols. S2 Parameters for births and deaths. S3 Parameters determining transmission and drugresistance. S4 Parameters determining disease progression. S5 Parameters determining disease relapse and natural cure. S6 Parameters related to treatment initiation and treatment success. S7 Scale up of drug sensitivity testing coverage in the "Policy" scenario in China. S8 RR/MDR-TB treatment regimens in the China "Policy" scenario. S9 Calibration targets-India Rates are expressed per 100,000 population. S10 Calibration targets-China. S11 China Incidence Target Data. S12 Modelled vaccine types and impact on disease states. S13 TB-related Unit Costs. S14 Vaccine-related Costs. S15 Willingness to Pay Thresholds. S16 Vaccine Impact by 50\% efficacy, 10-year P\&PI and PSI vaccines. $\mathbf{S 1 7}$ Incidence of TB disaggregated by origin.

Additional file 2. Consolidated Health Economic Evaluation Reporting Standards (CHEERS) checklist.

\section{Acknowledgements}

CKW was funded by the UK Medical Research Council (MRC) under the London School of Hygiene \& Tropical Medicine LID scholarship programme (MR/N013638/1). This research was funded by Aeras/IAVI. We thank Lixia Wang (Chinese Centre for Disease Control and Prevention) for country-level expert advice and Tom Sumner (LSHTM) and Gwenan Knight (LSHTM) for expert advice on model development. 


\section{Authors' contributions}

CKW undertook conceptualization, study design, data collection, programming, analysis and manuscript writing. RCH, GG and RGW undertook conceptualization study design and manuscript writing. RCH contributed to data validation. CFM and FB contributed to manuscript writing. FB contributed to data collection and validation. YR, RL, LT, KR and RR contributed to country-level data validation and manuscript writing. AG contributed to conceptualization and manuscript writing GBG and RGW contributed equally to this manuscript. All authors read and approved the final manuscript

\section{Funding}

MRC (MR/N013638/1); Aeras/IAVI

\section{Availability of data and materials}

The datasets used and/or analysed during the current study are available from the corresponding author on reasonable request.

\section{Ethics approval and consent to participate}

Not applicable

\section{Consent for publication}

Not applicable

\section{Competing interests}

GBG reports currently being employed at Sanofi Pasteur. RCH reports currently being employed at Sanofi Pasteur. RCH reports grants from IAVI, during the conduct of the study; personal fees from Sanofi Pasteur, unrelated to TB and outside the submitted work. Sanofi Pasteur did not provide funding for this work and had no role in study design, data collection, data analysis, data interpretation, or writing of the report. AG reports grants from Bill and Melinda Gates Foundation, grants from UK DFID, during the conduct of the study; and during this period, Aeras and IAVI (AG's employers during the time period) conducted TB vaccine clinical trials in collaboration with Sanofi and with GSK. However, neither paid any funds directly to AG or to Aeras or IAVI. All other authors declare no competing interests.

\section{Author details}

'TB Modelling Group, TB Centre and Centre for the Mathematical Modelling of Infectious Diseases, Department of Infectious Disease Epidemiology, Faculty of Epidemiology \& Population Health, London School of Hygiene and Tropical Medicine, London, UK. ${ }^{2}$ Currently employed at Sanofi Pasteur, Singapore, Singapore. ${ }^{3}$ Department of Global Health and Development, Faculty of Public Health \& Policy, London School of Hygiene and Tropical Medicine, London, UK. ${ }^{4}$ Chinese Centre for Disease Control and Prevention, Beijing, China. ${ }^{5}$ World Health Organisation, New Delhi, India. ${ }^{6}$ National Tuberculosis Elimination Programme, New Delhi, India. ${ }^{7}$ International AIDS Vaccine Initiative, New York, USA. ${ }^{8}$ Current Affiliation: Bill and Melinda Gates Foundation, Washington DC, USA. ${ }^{9}$ Currently employed at Sanofi Pasteur, Lyon, France.

\section{Received: 12 October 2020 Accepted: 29 January 2021}

\section{Published online: 26 February 2021}

\section{References}

1. Uplekar M, Weil D, Lonnroth K, Jaramillo E, Lienhardt C, Dias HM, et al. WHO's new End TB Strategy. Lancet. 2015;385:1799-801 doi:10/f3g5z3.

2. World Health Organization. Global Tuberculosis Report 2019. Geneva: World Health Organization; 2019.

3. Laurence YV, Griffiths UK, Vassall A. Costs to health services and the patient of treating tuberculosis: a systematic literature review. PharmacoEconomics. 2015;33:939-55 doi:10/f7qd66.

4. van den Hof S, Collins D, Hafidz F, et al. The socioeconomic impact of multidrug resistant tuberculosis on patients: results from Ethiopia, Indonesia and Kazakhstan. BMC Infect Dis. 2016;16:470. https://doi.org/10.1186/s12879016-1802-X.

5. Paterson DL. "Collateral damage" from cephalosporin or quinolone antibiotic therapy. Clin Infect Dis. 2004;38(Supplement_4):S341-5 doi:10/ fddncz.

6. Van Der Meeren O, Hatherill M, Nduba V, Wilkinson RJ, Muyoyeta M, Van Brakel E, et al. Phase $2 \mathrm{~b}$ controlled trial of M72/AS01E vaccine to prevent tuberculosis. N Engl J Med. 2018;379:1621-34 doi:10/gfb7kq.
7. Nemes E, Geldenhuys H, Rozot V, Rutkowski KT, Ratangee F, Bilek N, et al. Prevention of $\mathrm{M}$. tuberculosis infection with $\mathrm{H} 4: \mathrm{IC} 31$ vaccine or BCG revaccination. N Engl J Med. 2018;379:138-49 doi:10/gdwzpn.

8. Knight GM, Griffiths UK, Sumner T, Laurence YV, Gheorghe A, Vassall A, et al. Impact and cost-effectiveness of new tuberculosis vaccines in low- and middle-income countries. Proc Natl Acad Sci. 2014;111:15520-5 doi:10/ f6nj9t.

9. Tseng C-L, Oxlade O, Menzies D, Aspler A, Schwartzman K. Costeffectiveness of novel vaccines for tuberculosis control: a decision analysis study. BMC Public Health. 2011;11:55.

10. World Health Organization. Global Tuberculosis Report 2018. Geneva: World Health Organization; 2018. http://apps.who.int/iris/handle/10665/274453. Accessed 13 Nov 2018

11. Arinaminpathy N, Batra D, Khaparde S, Vualnam T, Maheshwari N, Sharma L, et al. The number of privately treated tuberculosis cases in India: an estimation from drug sales data. Lancet Infect Dis. 2016;16:1255-60 doi:10/ f874b8.

12. Fitzpatrick C, Hui Z, Lixia W, Renzhong L, Yunzhou R, Mingting C, et al. Cost-effectiveness of a comprehensive programme for drug-resistant tuberculosis in China. Bull World Health Organ. 2015;93:775-84 doi:10/ f7zwk9.

13. R Core Team. R: A Language and Environment for Statistical Computing Vienna; 2019. https://www.R-project.org/. Accessed 16 Apr 2020.

14. Harris RC, Sumner T, Knight GM, Evans T, Cardenas V, Chen C, et al. Agetargeted tuberculosis vaccination in China and implications for vaccine development: a modelling study. Lancet Glob Health. 2019;7:e209-18 doi: 10/ghk49b.

15. Harris RC, Sumner T, Knight GM, Zhang H, White RG. Potential impact of tuberculosis vaccines in China, South Africa, and India. Science Translational Medicine; 2020;12(564):eaax4607. https://doi.org/10.1126/scitransImed.aax4607.

16. Sensi P. History of the development of rifampin. Clin Infect Dis. 1983; 5(Supplement_3):S402-6 doi:10/csxf3z.

17. Murray JF, Schraufnagel DE, Hopewell PC. Treatment of tuberculosis. a historical perspective. Ann Am Thorac Soc. 2015;12:1749-59 doi:10/gf3mnc.

18. Fox W, Ellard GA, Mitchison DA. Studies on the treatment of tuberculosis undertaken by the British Medical Research Council tuberculosis units, 19461986, with relevant subsequent publications. Int J Tuberc Lung Dis Off J Int Union Tuberc Lung Dis. 1999;3(10 Suppl 2):S231-79.

19. Menzies D, Benedetti A, Paydar A, Martin I, Royce S, Pai M, et al. Effect of duration and intermittency of rifampin on tuberculosis treatment outcomes: a systematic review and meta-analysis. Plos Med. 2009;6:e1000146 doi:10/cjjjkc.

20. Johnston JC, Campbell JR, Menzies D. Effect of intermittency on treatment outcomes in pulmonary tuberculosis: an updated systematic review and metaanalysis. Clin Infect Dis. 2017;64:1211-20 doi:10/f94jht.

21. Schaaf HS, Collins A, Bekker A, Davies PDO. Tuberculosis at extremes of age. Respirology. 2010;15:747-63.

22. Swaminathan S, Rekha B. Pediatric tuberculosis: global overview and challenges. Clin Infect Dis. 2010;50(Supplement_3):S184-94 doi:10/c475k7.

23. Datta M, Swaminathan S. Global aspects of tuberculosis in children. Paediatr Respir Rev. 2001;2:91-6 doi:10/c7cksq.

24. Rajagopalan S, Yoshikawa TT. Tuberculosis in the elderly. Z Gerontol Geriatr. 2000;33:374-80.

25. Straetemans M, Glaziou P, Bierrenbach AL, Sismanidis C, van der Werf MJ. Assessing tuberculosis case fatality ratio: a meta-analysis. Plos One. 2011;6: e20755 doi:10/ck43kf.

26. Tiemersma EW, Werf MJ van der, Borgdorff MW, Williams BG, Nagelkerke NJD. Natural history of tuberculosis: duration and fatality of untreated pulmonary tuberculosis in HIV negative patients: a systematic review. Plos One. 2011;6:e17601. doi:10/ccsk8f.

27. Cohen T, Sommers B, Murray M. The effect of drug resistance on the fitness of Mycobacterium tuberculosis. Lancet Infect Dis. 2003;3:13-21 doi:10/bwqxpm.

28. Cohen T, Murray M. Modeling epidemics of multidrug-resistant M. tuberculosis of heterogeneous fitness. Nat Med. 2004;10:1117-21 doi:10/dzfxt8.

29. Knight GM, Zimic M, Funk S, Gilman RH, Friedland JS, Grandjean L. The relative fitness of drug-resistant Mycobacterium tuberculosis: a modelling study of household transmission in Peru. J R Soc Interface. 2018;15: 20180025 doi:10/gfvf52.

30. Kendall EA, Azman AS, Cobelens FG, Dowdy DW. MDR-TB treatment as prevention: The projected population-level impact of expanded treatment for multidrug-resistant tuberculosis. Plos One. 2017;12:e0172748 doi:10/ f9tcjw. 
31. World Health Organization. WHO Tuberculosis Database. 2018. http://www who.int/tb/country/data/download/en/. Accessed 23 Aug 2018.

32. Satyanarayana S, Nair SA, Chadha SS, Shivashankar R, Sharma G, Yadav S, et al. From where are tuberculosis patients accessing treatment in India? Results from a cross-sectional community based survey of 30 districts. Plos One. 2011;6:e24160 doi:10/c9mn96.

33. Yeole RD, Khillare K, Chadha VK, Lo T, Kumar AMV. Tuberculosis case notification by private practitioners in Pune, India: how well are we doing? Public Health Action. 2015;5:173-9.

34. Wang L, Zhang H, Ruan Y, Chin DP, Xia Y, Cheng S, et al. Tuberculosis prevalence in China, 1990-2010; a longitudinal analysis of national survey data. Lancet. 2014;383:2057-64 doi:10/f2sdjz.

35. Ministry of Health and Family Welfare, Government of India, World Health Organization. Report of the First National Anti-Tuberculosis Drug Resistance Survey India. 2018. https://tbcindia.gov.in/WriteReadData//892s/4187947827Na tional\%20Anti-TB\%20Drug\%20Resistance\%20Survey.pdf. Accessed 6 Apr 2018.

36. Ministry of Health and Family Welfare, Government of India. National Strategic Plan for Tuberculosis Elimination 2017-25. New Delhi: Government of India; 2017. https://tbcindia.gov.in/WriteReadData/NSP\%20Draft\%2020. 02.2017\%201.pdf. Accessed 25 Sept 2018

37. Lin H-H, Wang L, Zhang H, Ruan Y, Chin DP, Dye C. Tuberculosis control in China: use of modelling to develop targets and policies. Bull World Health Organ. 2015;93:790-8 doi:10/f7zwsd.

38. World Population Prospects 2019, Volume II: Demographic Profiles. :1238.

39. Read JM, Lessler J, Riley S, Wang S, Tan LJ, Kwok KO, et al. Social mixing patterns in rural and urban areas of southern China. Proc R Soc Lond B Biol Sci. 2014;281:20140268 doi:10/gf3mp5.

40. Mossong J, Hens N, Jit M, Beutels P, Auranen K, Massari M, et al. Social contacts and mixing patterns relevant to the spread of infectious diseases. Plos Med. 2008:5:e74 doi:10/ch2stb.

41. Dye C, Williams BG. Eliminating human tuberculosis in the twenty-first century. J R Soc Interface. 2008:5:653-62 doi:10/ch3qct.

42. Abu-Raddad LJ, Sabatelli L, Achterberg JT, Sugimoto JD, Longini IM Jr, Dye $C$, et al. Epidemiological benefits of more-effective tuberculosis vaccines, drugs, and diagnostics. Proc Natl Acad Sci U S A. 2009;106: 13980-5.

43. Dye C, Garnett GP, Sleeman K, Williams BG. Prospects for worldwide tuberculosis control under the WHO DOTS strategy. Lancet. 1998;352:188691 doi:10/c7r327.

44. Vynnycky E, Fine PE. The natural history of tuberculosis: the implications of age-dependent risks of disease and the role of reinfection. Epidemiol Infect. 1997;119:183-201 https://www.ncbi.nlm.nih.gov/pmc/articles/PMC2808840/. Accessed 10 Dec 2017.

45. Gabriela M, Gomes M, Rodrigues P, Hilker FM, Mantilla-Beniers NB, Muehlen M, Cristina Paulo A, et al. Implications of partial immunity on the prospects for tuberculosis control by post-exposure interventions. J Theor Biol. 2007; 248:608-17. https://doi.org/10.1016/j.jtbi.2007.06.005.

46. Schulzer M, Fitzgerald JM, Enarson DA, Grzybowski S. An estimate of the future size of the tuberculosis problem in sub-Saharan Africa resulting from HIV infection. Tuber Lung Dis. 1992;73:52-8.

47. Yoshikawa TT. Tuberculosis in aging adults. J Am Geriatr Soc. 1992;40:178-87.

48. High K, Marion C. Tuberculosis in Older Adults. In: Yoshikawa T, Norman D, editors. Infectious Disease in the Aging: A Clinical Handbook. 2nd edition. Totowa: Humana Press; 2009:97-110.

49. Ferebee $\mathrm{SH}$. Controlled chemoprophylaxis trials in tuberculosis. A general review. Bibl Tuberc. 1970;26:28-106.

50. Marx FM, Dunbar R, Enarson DA, Williams BG, Warren RM, Spuy VD, et al. The temporal dynamics of relapse and reinfection tuberculosis after successful treatment: a retrospective cohort study. Clin Infect Dis. 2014;58: 1676-83 doi:10/f5983d.

51. Perriëns JH, St. Louis ME, Mukadi YB, Brown C, Prignot J, Pouthier F, et al. Pulmonary tuberculosis in HIV-infected patients in Zaire - a controlled trial of treatment for either 6 or 12 months. N Engl J Med. 1995;332:779-85 doi: 10/fwzgmx.

52. Sharifi-Mood B, Metanat M, Alavi-Naini R, Kouhpayeh $H-R$, Salehi M, Naderi $M$, et al. The comparison of six-month and four-month regimens of chemotherapy in the treatment of smear positive pulmonary tuberculosis. J Med Sci. 2006;6:108-11 doi:10/cmnd89.

53. Felten MK. Importance of rifampicin in combined daily/intermittent chemotherapy for tuberculosis. South Afr Med J Suid-Afr Tydskr Vir Geneeskd. 1989;75:524-6.
54. Combs DL. USPHS tuberculosis short-course chemotherapy trial 21: effectiveness, toxicity, and acceptability: the report of final results. Ann Intern Med. 1990;112:397 doi:10/gf3mvt.

55. Holtz TH, Sternberg M, Kammerer S, Laserson KF, Riekstina V, Zarovska E, et al. Time to sputum culture conversion in multidrug-resistant tuberculosis: predictors and relationship to treatment outcome. Ann Intern Med. 2006; 144:650 doi:10/f3vpd3.

56. World Health Organization. Guidelines for the treatment of drug-susceptible tuberculosis and patient care, 2017 update. World Health Organization; 2017. http://www.who.int/iris/handle/10665/255052. Accessed 18 Dec 2017.

57. World Health Organization. WHO consolidated guidelines on drug-resistant tuberculosis treatment. 2019. http://www.ncbi.nlm.nih.gov/books/NBK53951 7/. Accessed 7 Aug 2019.

58. Xu C, Pang Y, Li R, Ruan Y, Wang L, Chen M, et al. Clinical outcome of multidrug-resistant tuberculosis patients receiving standardized second-line treatment regimen in China. Journal of Infection. 2018;76:348-53.

59. World Health Organization. Global tuberculosis report 2016. 2016

60. Harris RC. Informing development strategies for new tuberculosis vaccines: mathematical modelling and novel epidemiological tools. Doctoral Thesis. London School of Hygiene \& Tropical Medicine; 2018. http://researchonline. Ishtm.ac.uk/4648987/. Accessed 2 Sept 2018.

61. Funk S. socialmixr: R package for deriving social mixing matrices from survey data. R. 2017. https:/github.com/sbfnk/socialmixr. Accessed 28 Nov 2017.

62. Sunnåker $M$, Busetto AG, Numminen E, Corander J, Foll M, Dessimoz C. Approximate Bayesian Computation. Plos Comput Biol. 2013;9:e1002803 doi: $10 / f 4 n 6 d w$.

63. Wegmann D, Leuenberger C, Excoffier L. Efficient Approximate Bayesian Computation Coupled With Markov Chain Monte Carlo Without Likelihood. Genetics. 2009;182:1207-18 doi:10/bk49wn.

64. Pandey S, Chadha VK, Laxminarayan R, Arinaminpathy N. Estimating tuberculosis incidence from primary survey data: a mathematical modeling approach. Int J Tuberc Lung Dis. 2017;21:366-74 doi:10/gf3mgz.

65. Shen X, DeRiemer K, Yuan Z, Shen M, Xia Z, Gui X, et al. Deaths among tuberculosis cases in Shanghai, China: who is at risk? BMC Infect Dis. 2009;9: 95 doi:10/br8c9q.

66. Wang WB, Zhao Q, Yuan ZA, Jiang WL, Liu ML, Xu B. Deaths of tuberculosis patients in urban China: a retrospective cohort study. Int J Tuberc Lung Dis. 2013;17:493-8.

67. Cheng J, Wang L, Zhang H, Xia Y. Diagnostic Value of Symptom Screening for Pulmonary Tuberculosis in China. PLoS ONE. 2015;10(5):e0127725. https://doi.org/10.1371/journal.pone.0127725.

68. Glaziou P, Dodd PJ, Zignol M, Sismanidis K, Floyd K. Online Technical Appendix: WHO Global Tuberculosis Report 2018. https://www.who.int/tb/ publications/global_report/gtbr2018_online_technical_appendix_global_ disease_burden_estimation.pdf?ua=1. Accessed 12 Feb 2020.

69. Zhao Y, Xu S, Wang L, Chin DP, Wang S, Jiang G, et al. National survey of drugresistant tuberculosis in China. N Engl J Med. 2012;366:2161-70 doi:10/gf3msc.

70. World Health Organisation. Global Tuberculosis Report 2017. Geneva: World Health Organizaton; 2017. http://apps.who.int/iris/bitstream/10665/2593 66/1/9789241565516-eng.pdf. Accessed 21 Nov 2017

71. Dodd PJ, Sismanidis C, Seddon JA. Global burden of drug-resistant tuberculosis in children: a mathematical modelling study. Lancet Infect Dis. 2016;16:1193-201 doi:10/f84cgc.

72. Tait DR, Hatherill M, Van Der Meeren O, Ginsberg AM, Van Brakel E, Salaun $B$, et al. Final Analysis of a Trial of M72/AS01E Vaccine to Prevent Tuberculosis. N Engl J Med. 2019;381:2429-39 doi:10/ggfnc4.

73. World Health Organization. WHO preferred product characteristics for new tuberculosis vaccines. Technical documents. World Health Organization; 2018. http://apps.who.int/iris/handle/10665/273089. Accessed 16 Nov 2018.

74. HPV Information Centre. Human Papillomavirus and Related Diseases Report. Institut Català d'Oncologia; 2017. http://www.hpvcentre.net/sta tistics/reports/ZAF.pdf. Accessed on 16 Apr 2020.

75. UNESCO Institute for Statistics. Education: gross enrolment ratio by level of education. UIS.Stat. http://data.uis.unesco.org/?queryid=142. Accessed 16 Apr 2020.

76. Harouna DM. Roll out of the meningococcal a conjugate vaccine through mass vaccination campaigns in countries of the African meningitis belt; 2014.

77. Wu S, Yang P, Li H, Ma C, Zhang Y, Wang Q. Influenza vaccination coverage rates among adults before and after the 2009 influenza pandemic and the reasons for non-vaccination in Beiijing, China: a cross-sectional study. BMC Public Health. 2013;13:636 doi:10/gbdckm. 
78. Zheng Y, Yang P, Wu S, Ma C, Seale H, Macintyre CR, et al. A cross-sectional study of factors associated with uptake of vaccination against influenza among older residents in the postpandemic season in Beijing, China. BMJ Open. 2013:3:e003662 doi:10/gb3vt9.

79. Das BR, Kakoti G, Bahety H, Das N, Medhi AH. Adult Japanese encephalitis mass vaccination campaign: a rapid convenience assessment. Int J Curr Res Acad Rev. 2014:2:30-6.

80. Vassall A, Sweeney S, Kahn J, Gomez GB, Bollinger L, Marseille E, et al. Reference Case for Estimating the Costs of Global Health Services and Interventions. Global Health Cost Consortium; 2017. https://ghcosting.org/ pages/standards/reference_case. Accessed 16 Apr 2020.

81. Mijiti P, Yuehua L, Feng X, Milligan PJ, Merle C, Gang W, et al. Prevalence of pulmonary tuberculosis in western China in 2010-11: a population-based, cross-sectional survey. Lancet Glob Health. 2016;4:e485-94 doi:10/f8sddr.

82. Chatterjee $S$, Das $P$, Nigam A, et al. Variation in cost and performance of routine immunisation service delivery in India BMJ Global Health. 2018;3: e000794.

83. Department of Health and Family Welfare, Ministry of Health and Family Welfare. Introduction of Measles-Rubella Vaccine National Operational Guidelines. New Delhi, India; 2017. https://main.mohfw.gov.in/sites/default/ files/195431585071489665073.pdf. Accessed 1 May 2020.

84. Yu W, Lu M, Wang H, Rodewald L, Ji S, Ma C, et al. Routine immunization services costs and financing in China, 2015. Vaccine. 2018;36:3041-7 doi:10/ gdpgsn.

85. Yin Z, Beeler Asay GR, Zhang L, Li Y, Zuo S, Hutin YJ, et al. An economic evaluation of the use of Japanese encephalitis vaccine in the expanded program of immunization of Guizhou province, China. Vaccine. 2012;30: 5569-77 doi:10/gf3msd.

86. Hutton DW, So SK, Brandeau ML. Cost-effectiveness of nationwide hepatitis B catch-up vaccination among children and adolescents in China. Hepatology. 2010;51:405-14 doi:10/frfrhg.

87. Floyd K, Arora VK, Murthy KJR, Lonnroth K, Singla N, Akbar Y, et al. Cost and cost-effectiveness of PPM-DOTS for tuberculosis control: evidence from India. Bull World Health Organ. 2006;84:437-45 https://www.ncbi.nlm.nih. gov/pmc/articles/PMC2627367/. Accessed 30 Mar 2020.

88. Pantoja A, Lönnroth K, Lal SS, Chauhan LS, Uplekar M, Padma MR, et al. Economic evaluation of public-private mix for tuberculosis care and control, India. Part II. Cost and cost-effectiveness. Int J Tuberc Lung Dis. 2009;13:70512.

89. Rupert S, Vassall A, Raizada N, Khaparde SD, Boehme C, Salhotra VS, et al. Bottom-up or top-down: unit cost estimation of tuberculosis diagnostic tests in India. Int J Tuberc Lung Dis. 2017;21:375-80.

90. Department of Community Medicine \& School of Public Health, Post Graduate Institute of Medical Education and Research (PGIMER) Chandigarh, Department for Health Research, Ministry of Health \& Family Welfare, Health Technology Assessment in India, Public Health Foundation of India, Indian Institute of Techology, Madras, Tata Institute of Social Science. National Health System Cost Database for India. National Health System Cost Database for India. https://www.healtheconomics.pgisph.in/costing_web/ index.php?action=Cost_data. Accessed 31 Mar 2020.

91. Stop TB. Partnership. Medicines \& Diagnostics Catalog - Global Drug Facility. Geneva: Stop TB Partnership; 2020.

92. Gotham D, Fortunak J, Pozniak A, Khoo S, Cooke G, Nytko FE, et al. Estimated generic prices for novel treatments for drug-resistant tuberculosis. J Antimicrob Chemother. 2017;72:1243-52 doi:10/f9xv65.

93. World Health Organization. WHO-CHOICE. WHO. http://www.who.int/ choice/en/. Accessed 18 Feb 2020

94. Wang G, Wang S, Jiang G, Fu Y, Shang Y, Huang H. Incremental costeffectiveness of the second Xpert MTB/RIF assay to detect Mycobacterium tuberculosis. J Thorac Dis. 2018;10:1689-95 doi:10/ghk49k.

95. Salomon JA, Haagsma JA, Davis A, Noordhout CM de, Polinder S, Havelaar $\mathrm{AH}$, et al. Disability weights for the Global Burden of Disease 2013 study. Lancet Glob Health. 2015;3:e712-23. doi:10/gf3mm4.

96. World Health Organization. WHO | Metrics: Disability-Adjusted Life Year (DALY). Health Statistics and Information Systems. 2014. http://www.who. int/healthinfo/global_burden_disease/metrics_daly/en/. Accessed 22 Aug 2018.

97. Claxton KP, Revill P, Sculpher M, Wilkinson T, Cairns J, Briggs A. The gates reference case for economic evaluation. Seattle: Bill Melinda Gates Found; 2014.
98. World Health Organization. Gear up to end TB: Introducing the end TB Strategy. Technical documents. World Health Organization; 2015. http://a pps.who.int/iris/handle/10665/156394. Accessed 15 Nov 2018.

99. Lönnroth K, Raviglione M. The WHO's new End TB Strategy in the post-2015 era of the Sustainable Development Goals. Trans R Soc Trop Med Hyg. 2016; 110:148-50 doi:10/gf3mkb.

100. WHO Commission on Macroeconomics and Health. Macroeconomics and health : investing in health for economic development : executive summary. Geneva: World Health Organization; 2001. https://apps.who.int/ iris/handle/10665/42463. Accessed 20 Feb 2020

101. Ochalek J, Lomas J, Claxton K. Estimating health opportunity costs in lowincome and middle-income countries: a novel approach and evidence from cross-country data. BMJ Glob Health. 2018;3:e000964 doi:10/gfj36h.

102. Husereau D, Drummond M, Petrou S, Carswell C, Moher D, Greenberg D, et al. Consolidated Health Economic Evaluation Reporting Standards (CHEE RS) statement. BMC Med. 2013;11:80 doi:10/gb33pb.

103. Kendall EA, Fofana MO, Dowdy DW. Burden of transmitted multidrug resistance in epidemics of tuberculosis: a transmission modelling analysis. Lancet Respir Med. 2015;3:963-72 doi:10/f733ph.

104. Sharma A, Hill A, Kurbatova E, van der Walt M, Kvasnovsky C, Tupasi TE, et al. Estimating the future burden of multidrug-resistant and extensively drug-resistant tuberculosis in India, the Philippines, Russia, and South Africa: a mathematical modelling study. Lancet Infect Dis. 2017;17:707-15 doi:10/ b624.

105. Zwerling A, Behr MA, Verma A, Brewer TF, Menzies D, Pai M. The BCG World Atlas: a database of global BCG vaccination policies and practices. Plos Med. 2011;8:e1001012. https://doi.org/10.1371/journal.pmed.1001012.

106. Mangtani P, Abubakar I, Ariti C, Beynon R, Pimpin L, Fine PEM, et al. Protection by $B C G$ vaccine against tuberculosis: a systematic review of randomized controlled trials. Clin Infect Dis. 2014;58:470-80 doi:10/f5r7r2.

107. Abubakar I, Pimpin L, Ariti C, Beynon R, Mangtani P, JAC S, et al. Systematic review and meta-analysis of the current evidence on the duration of protection by bacillus Calmette-Guérin vaccination against tuberculosis. Health Technol Assess Winch Engl. 2013;17:1-372 v-vi.

108. Fifteen year follow up of trial of BCG vaccines in south India for tuberculosis prevention. Tuberculosis Research Centre (ICMR), Chennai. Indian J Med Res. 1999;110:56-69.

109. Randomised controlled trial of single BCG, repeated BCG, or combined BCG and killed Mycobacterium leprae vaccine for prevention of leprosy and tuberculosis in Malawi. Karonga Prevention Trial Group. Lancet Lond Engl. 1996;348:17-24

\section{Publisher's Note}

Springer Nature remains neutral with regard to jurisdictional claims in published maps and institutional affiliations.

Ready to submit your research? Choose BMC and benefit from:

- fast, convenient online submission

- thorough peer review by experienced researchers in your field

- rapid publication on acceptance

- support for research data, including large and complex data types

- gold Open Access which fosters wider collaboration and increased citations

- maximum visibility for your research: over $100 \mathrm{M}$ website views per year

At $\mathrm{BMC}$, research is always in progress.

Learn more biomedcentral.com/submissions 